\title{
Selection improves Sevin resistance in spider mite predator
}

\section{Field trials have documented the genetic improvement of an important biological control agent in almond orchards}

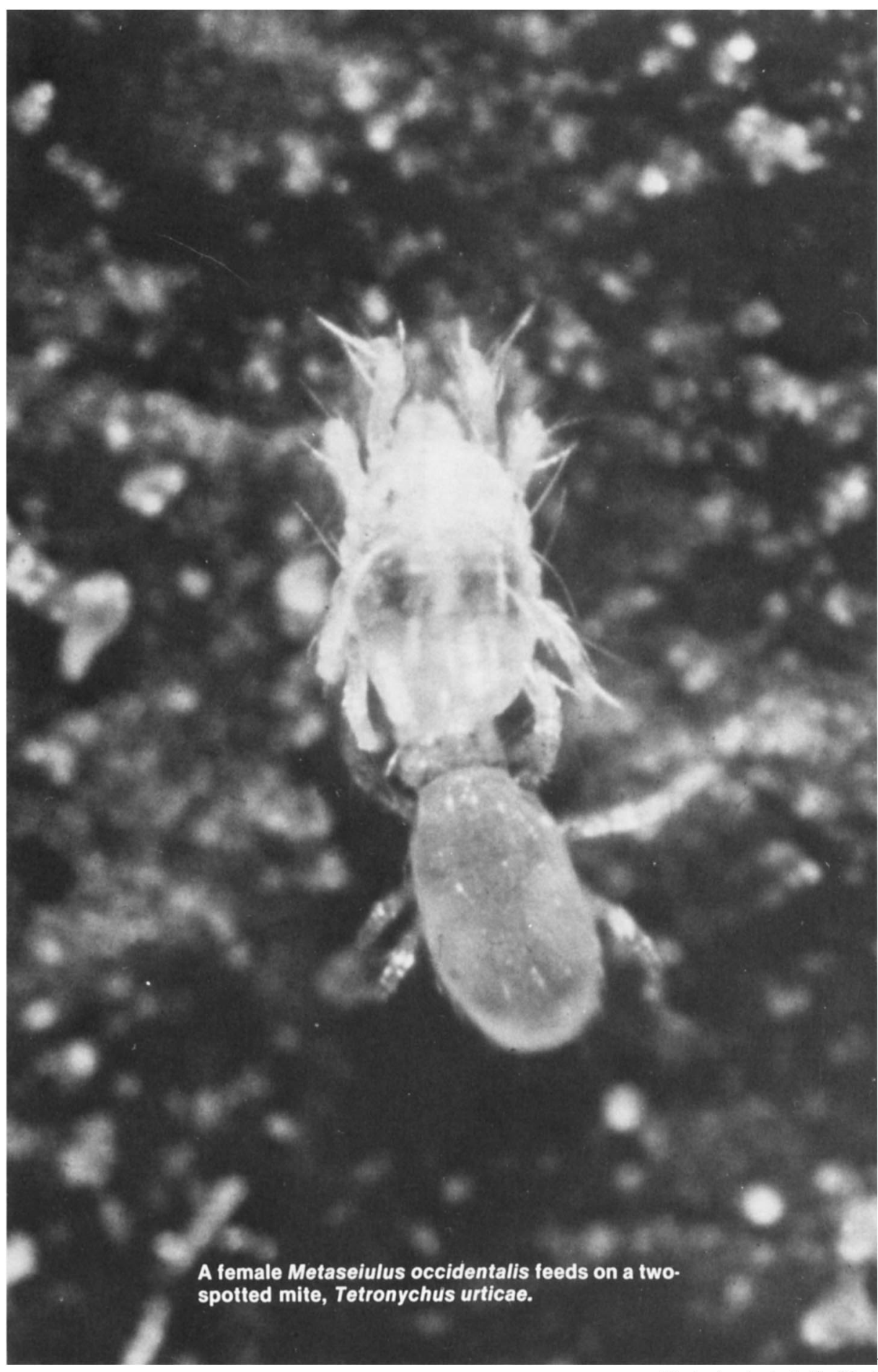

-Photo by Jack Kelly Clark

Richard T. Roush $\square$ Marjorie A. Hoy

$\mathbf{S}$ estimated $\$ 60$ million in crop losses and pest control expenditures in 1977. Their ability to tolerate or resist pesticides which destroy their predators accounts for their economic significance.

Some spider mite predators, the phytoseiid mites, have developed resistance to some insecticides in nature. One such predator, Metaseiulus (= Typhlodromus) occidentalis (Nesbitt), has developed widespread resistance to organophosphorus insecticides such as azinphosmethyl (Guthion), important in apple and pear pest management in Washington and California.

Unfortunately, $M$. occidentalis has not developed resistance to all pesticides used in those crops where it can be effective in minimizing spider mite outbreaks. Carbaryl (Sevin) is one example. Some of its uses include blossom thinning in apples and navel orangeworm (Amyelois $(=$ Paramyelois) transitella (Walker)) control in almonds.

\section{Genetic selection program}

A genetic selection program to develop a carbaryl-resistant strain of $M$. occidentalis began in December 1977. The first step involved mass hybridization of $M$. occidentalis colonies collected from 18 locations in California and Washington to provide adequate genetic variability. None of these colonies was detectably resistant to carbaryl. Two genetic selection methods were used. One method involved rearing predators and prey on pinto bean plants and spraying them with increasing doses of formulated carbaryl. The other method involved treating just the immature, motile stages and adult males on pieces of moistened filter paper. About 500 to 1000 predators were treated in each round of selection to give about 70 to 90 percent mortality.

A "leaf flood" method was adopted to quantify $M$. occidentalis' responses to carbaryl: bean leaf discs were placed on moist 
cotton and flooded with a "challenge" dose of 2 pounds (active ingredient) carbaryl ( 80 percent wettable powder) per 100 gallons of water. Gravid adult female predators were then floated in the pesticide which was allowed to dry. Tetranychus urticae Koch, the two-spotted spider mite, was added to the leaflets after the carbaryl dried as prey, and the leaf discs were held at $28^{\circ} \mathrm{C}$ for 48 hours when the number of survivors was recorded. Ten females were tested on each of ten leaf discs (100 predators total) for each assay.

A high level of resistance developed in $M$. occidentalis strains selected by both methods. After 15 to 19 rounds of selection, about 83 percent of the selected strains survived compared with about 2 percent in the unselected strains. Genetic crosses indicated that the carbaryl resistance is inherited as a single incompletely dominant gene. The $F_{1}$ hybrids (offspring resulting from the mating of resistant and susceptible parents) survived the "challenge" dose nearly as well (72 percent) as their resistant parents.

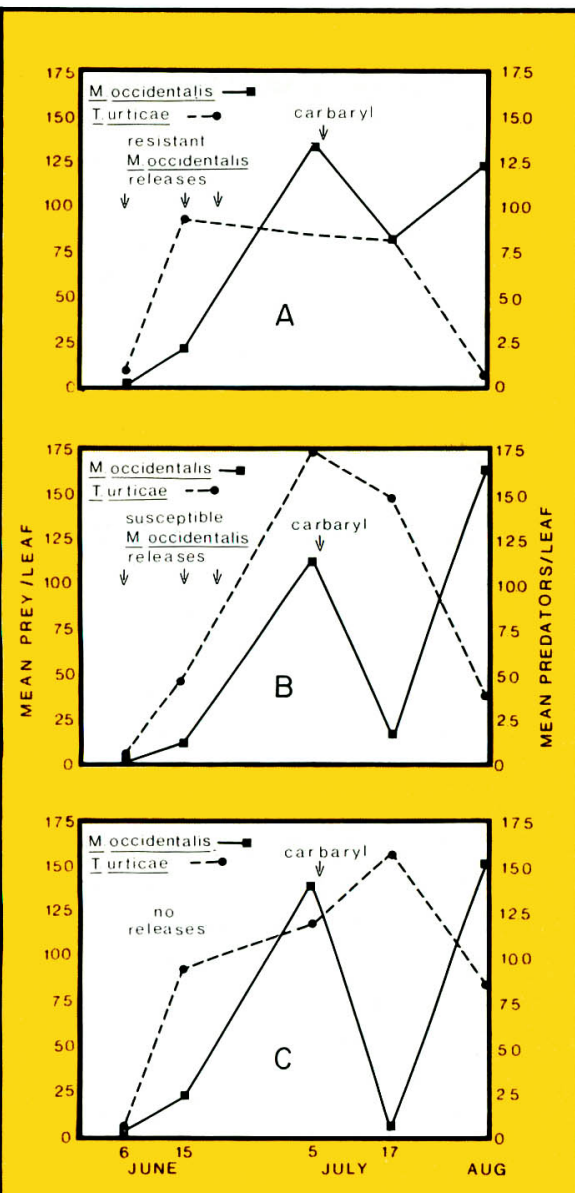

Fig. 1. Visalia Almond Orchard, 1979: (A) trees where resistant predators were released (RR); (B) trees where susceptible predators were released (SR); (C) trees where no releases were made (NR).
Laboratory and greenhouse tests examined the vigor of these laboratory-selected predators in the absence of carbaryl treatments. Traits evaluated included: reproductive rate, development rate, sex ratio, mating preferences and compatibilities, diapause capacity (ability to enter their overwintering state), azinphosmethyl resistance, and capacity to control spider mite populations. Pesticide-resistant strains of insects and mites often develop slowly and/or produce fewer eggs than do susceptible (wild type) strains, but these strains do not. In fact, based on one greenhouse experiment, a population of these resistant predators may increase faster than those of the susceptible predator strains tested. The sex ratio may have increased so that more females are produced than normal.

The carbaryl-resistant predators mate freely and seem reproductively compatible with California $M$. occidentalis populations. Their diapause capacity seems normal and their resistance to azinphosmethyl increased, although the predators were never exposed to this insecticide during the selection program. Two greenhouse tests demonstrated that the carbaryl-resistant predators could survive a normal application of carbaryl and control two-spotted spider mites on pinto beans.

The carbaryl resistance in these predator strains doesn't appear to break down over time. $M$. occidentalis populations with equal numbers of resistant and susceptible genes (i.e., Fl hybrid progeny of resistant $X$ susceptible parents) retained the expected level of resistance ( 51 percent survival at the 2-pound challenge dose) for 8 months (about 16 to 24 generations) when maintained on pinto bean plants in the greenhouse which were not treated with carbaryl.

\section{Field releases}

Laboratory and greenhouse assessments of this genetically-selected strain indicated that it should perform well in the field. To assess their effectiveness in the field, the resistant predators were reared on the twospotted spider mite on pinto beans, released into two almond orchards, and sprayed with carbaryl applied for navel orangeworm control during 1979. There were three objectives: (1) to determine whether the predators could survive the carbaryl applications; (2) to determine whether the surviving predators could control spider mite populations in these almond trees and (3) to determine whether the resistance characteristic could persist for more than one season.
The almond orchards used were a research orchard near Visalia and a commercial orchard near Blackwell's Corner, Kern County. The Visalia orchard is closely planted with less than one foot between the foliage of trees. The trees had also been radically pruned and therefore produced leaves about four times larger than those at the Blackwell's Corner orchard. Seven trees in each orchard were randomly assigned to each of three treatments: (1) no releases (NR); (2) release-susceptible (unselected) laboratory-reared predators (SR); and (3) release-resistant (selected) laboratory-reared predators (RR). All 21 trees in a given orchard were contiguous in one or two rows, i.e., there were no "guard" trees between experimental trees. Untreated

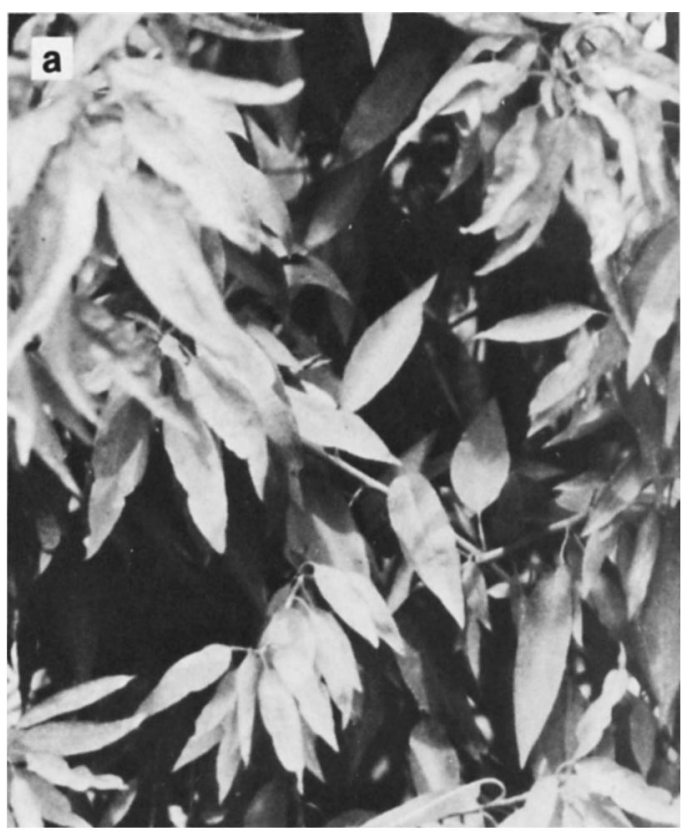

Fig. 2. Closeup of foliage at the Visalia orchard, showing the relative conditions of trees where $(A)$ resistant predators were released (RR) and (B) susceptible predators were released (SR). 
check trees were within three rows of both test plots.

Azinphosmethyl (4 lbs $50 \%$ WP/acre) was applied with a speed sprayer on May 17 at the Visalia orchard to precipitate a spider mite outbreak. A total of $3500 \mathrm{M}$. occidentalis were then released per tree between June 6 and June 20. On July 6 carbaryl $80 \mathrm{WP}$ was applied at the rate of 10 $\mathrm{lb} /$ acre as a dilute spray (Ca $400 \mathrm{gal} / \mathrm{acre}$ ), using a handgun. One thousand predators were released per tree on June 14 in the Blackwell's Corner orchard. On July 13 carbaryl 80 WP was applied at the rate of 7 $\mathrm{lb} / \mathrm{acre}$ as a concentrate spray (approximately $35 \mathrm{gal} / \mathrm{acre}$ ) by helicopter. Thirty leaves were randomly sampled per tree and counted by a leaf brushing method. The

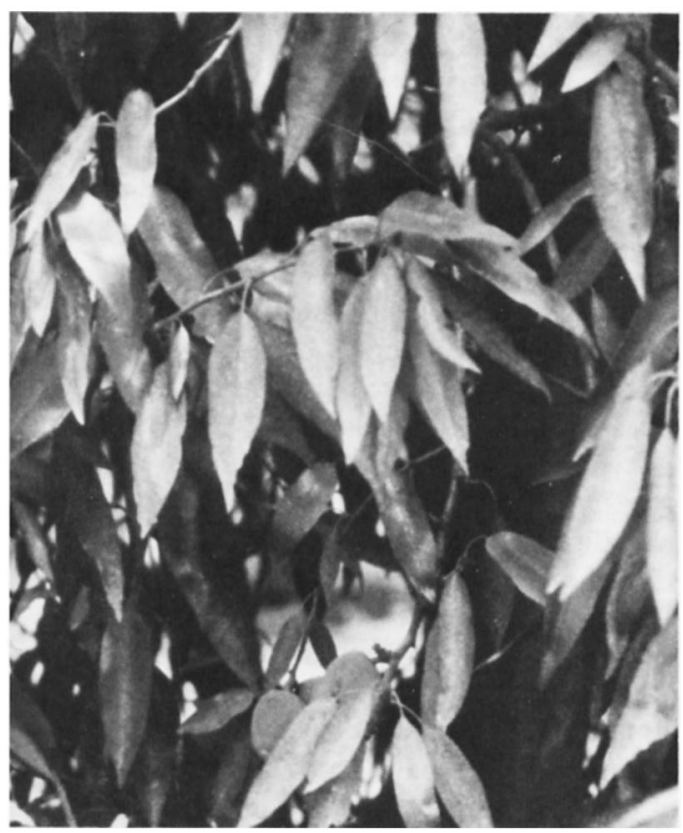

mean totals of all stages are given in the figures.

To document that the predators found on the trees after the carbaryl application were resistant, a sample of predators collected on August 1 was colonized in the laboratory and tested for carbaryl resistance. A colony collected before the predator releases were made was tested for comparison. This was necessary because it is possible that the $M$. occidentalis found on a tree after a carbaryl application may have survived because of incomplete coverage or they may have migrated to the tree after the carbaryl application. These predators need not be resistant.

\section{Results of field releases}

None of the predator releases caused any statistically significant increases in the predator populations before the carbaryl treatments at either orchard.

In both orchards, the resistant predators survived the carbaryl application and controlled the spider mite populations, whereas the susceptible predators did not. The principal mite species in the Visalia orchard was the two-spotted spider mite. The May azinphosmethyl application produced a spider mite population greater than that desired. Some defoliation and considerable webbing were evident before the carbaryl application on July 6. The carbaryl application appeared to cause a slight decrease in the $M$. occidentalis populations in the RR trees (where resistant predators were released), figure $1 \mathrm{~A}$, but this decrease was not statistically significant and is probably because of mortality of a large proportion of the native susceptible predators

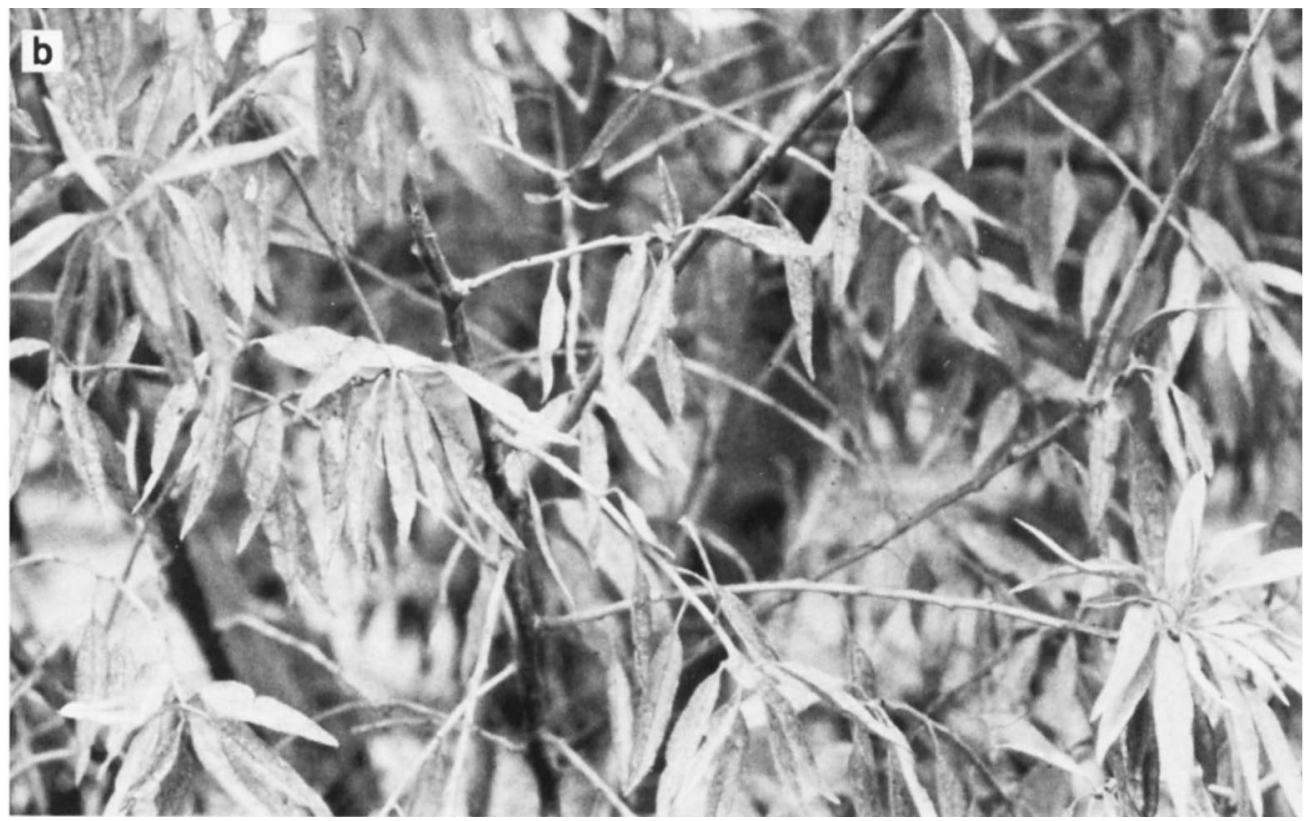

also present on the trees (as illustrated by the insignificant impact of 3500 released predators per tree). There was a significant decrease in predator populations in the other (SR and NR) trees $(P<.008$, signed rank test, figures $1 \mathrm{~B}, \mathrm{C}$ ).

Although there were no significant differences in $M$. occidentalis or spider mite populations in the Visalia orchard before the carbaryl application, there were more predators $(P<.001)$ and fewer spider mites $(P<.01$, Mann-Whitney $U$ test $)$ in the $R R$ trees (figure 1A) on July 17 (after the application). In spite of decreases in predator populations on the non-release (NR) and susceptible release (SR) trees (July 17, figures $1 \mathrm{~B}, \mathrm{C})$, there were no great increases in spider mite populations as are often observed after a carbaryl application. This is probably because of the poor nutritional quality of the almond leaves at that time. The differences in $T$. urticae populations persisted through August 1, even though the differences in predator numbers became insignificant because of predator reproduction. The proportion of defoliation was much less in the RR trees (figure $2 A$ ) than in the other trees (figure 2B).

The resistant predators successfully colonized the Blackwell's Corner orchard, even though the spider mite populations were very low, and kept the spider mites in low numbers. The principal spider mite species in this orchard was the Pacific spider mite, Tetranychus pacificus McGregor. There were no significant differences in the predator and prey population densities at the Blackwell's Corner orchard until the August 1 sample when the trees containing resistant predators (figure 3A) had significantly lower Pacific mite densities than the other trees (Mann-Whitney $\mathrm{U}$ test, $\mathrm{P}<.05$ ). There were, however, no statistically significant differences in $M$. occidentalis populations.

Apparently, as in the Visalia orchard, the predators on the $R \mathbf{R}$ trees survived the carbaryl application in sufficient numbers to control the spider mite populations (figure $3 \mathrm{~A}$ ), but the trees with the susceptible predators (SR and NR) suffered a Pacific spider mite population increase (figures 3B, 3C). Unfortunately, the initial populations of the predators were too low and the samples taken at an inappropriate time to show statistical differences in the numbers of $M$. occidentalis in the first post-application sample (as was possible in the Visalia orchard). No Pacific spider mites could be found in this plot on August 17, probably because of their depletion by the $M$. occidentalis populations. There was no defoliation in any of these trees. 
The results of the $2 \mathrm{lb} \mathrm{AI} / 100$ gal leaf flood tests on the predators recovered from the test plots on August 1 show that the released resistant predators were responsible for controlling the spider mites. The predators recovered from the RR trees at the Visalia orchard on August 1 are more resistant to carbaryl (survival: 71 percent) than are those collected from the SR and NR trees (34 percent, $\mathrm{P}<.001$ ). But even the predators from the NR and SR trees are more resistant than the native (pre-release) population ( 2 percent, $\mathrm{P}<.01$ ), which suggests that some of the resistant predators have dispersed among these closely spaced trees.

The predators on the resistant release trees are significantly more resistant (63 percent survival) than are those collected from the SR and NR trees (7 percent, $P<$ $.001)$. The resistances on these trees are unchanged from their pre-release levels. The trees in this orchard are more widely spaced, so dispersal among these trees was probably lower than at the Visalia orchard.

The levels of resistance exhibited by the M. occidentalis collected from the RR trees in these two orchards are well within the ranges expected from the resistance levels of the laboratory strains (table 1) because some susceptible genes would undoubtedly "survive" the carbaryl application in heterozygotes ( $\mathrm{F}_{1}$ predators). Some susceptible (homozygote) predators would be produced as the predators continued to mate randomly.

The work described up to this point documents two of the objectives of this genetic improvement project: predator survival after field applications of carbaryl and prey regulation. That the resistant preda- tors could be established even at very low prey densities and survive to control the spider mites in the Blackwell's Corner orchard is particularly impressive.

The third objective was to show that the resistance trait can persist in these predator populations from year to year. This phase of the project will require further study, and because of a variety of environmental

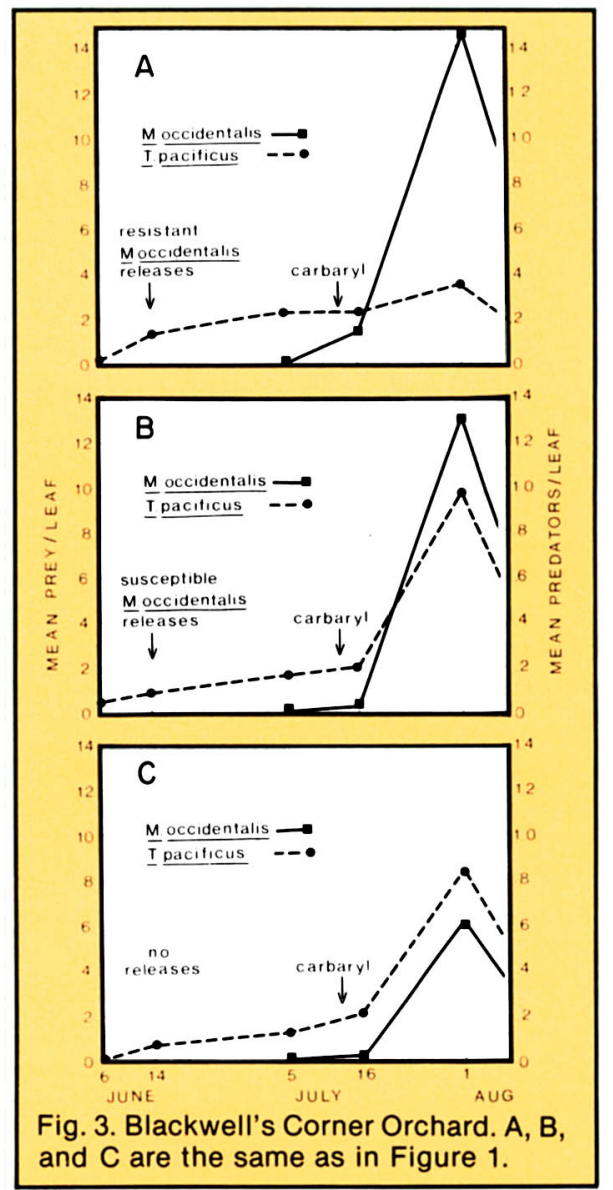
and $C$ are the same as in Figure 1.

\begin{tabular}{|c|c|}
\hline \multicolumn{2}{|c|}{$\begin{array}{l}\text { TABLE 1. Survivorship of Gravid Females from M. occidentalis Colonies } \\
\text { Treated with a Carbaryl Challenge Dose (2 Ib Al/100 gal). }\end{array}$} \\
\hline & $\begin{array}{l}\text { Survival* } \\
\text { (percent) }\end{array}$ \\
\hline \multicolumn{2}{|l|}{ Visalia orchard } \\
\hline Colony collected before predators were released & $2 \mathrm{c}$ \\
\hline \multicolumn{2}{|l|}{ Colony collected August 1 from trees where } \\
\hline resistant predators were released (RR) & $71 \mathrm{a}$ \\
\hline \multicolumn{2}{|l|}{$\begin{array}{l}\text { Combined colony collected August } 1 \text { from trees } \\
\text { where susceptible predators were released and }\end{array}$} \\
\hline where no predators were released (SR and NR) & $34 \mathrm{~b}$ \\
\hline \multicolumn{2}{|l|}{ Blackwell's Corner orchard } \\
\hline \multirow{2}{*}{\multicolumn{2}{|c|}{ Colony collected August 1 from trees where }} \\
\hline & \\
\hline resistant predators were released (RR) & 63 aa \\
\hline \\
\hline where no predators were released (SR and NR) & $7 \mathrm{bb}$ \\
\hline \multicolumn{2}{|l|}{ Laboratory strains } \\
\hline Resistant strain & 83 \\
\hline Susceptible strain & 2 \\
\hline F1 progeny & 72 \\
\hline F2 progeny & 51 \\
\hline
\end{tabular}

vagaries, full documentation of this aspect may take some time. However, as a preliminary test of overwintering ability and persistence, a strain less resistant than the one used in this project (from the ninth selection) was released in the Blackwell's Corner orchard in August 1978. This strain did successfully persist through June 1979 . The predators were difficult to find in June 1979 because of the low Pacific spider mite populations (figure 3 ), but $3 \mathrm{M}$. occidentalis were collected from a resistant release tree and one was collected from a susceptible release tree. A laboratory colony formed from the 3 predators from the RR tree had a challenge dose survivorship of 21 percent which was significantly greater $(P$ $=.05$ ) than that of the colony founded by the predator from the NR tree. Unfortunately, the colonies tested are from small samples and the data are suggestive rather than conclusive.

Full acceptance of the value of these resistant predators for pest management will require larger field plots and longer trials. We expect that resistance levels will increase as additional carbaryl applications cull the susceptible predators in the orchards. Tests of predator efficacy will require study sites where high rates of acaricides are not routinely used. Although acaricides such as propargite (Omite) and cyhexatin (Plictran) kill few M. occidentalis directly, some spider mites must survive the acaricide application or all the predators will starve in about 10 days. If that happens, wind-blown spider mites can return to the orchard and rapidly build up in the absence of predators.

Entomologists have noted the successes of plant and animal breeders and have discussed selective breeding of improved strains of natural enemies for more than 60 years. Honeybees, silkworms, and other domesticated or semi-domesticated insects have been "improved" by selection, but no one has documented genetic improvement of a biological control agent's field effectiveness until now. We believe that this is the first successful field demonstration of its kind. We also believe that genetic improvement projects will eventually be successful for other species of biological control agents and can involve attributes other than pesticide resistance.

Richard $T$ Roush is a graduate student and Marjorie A. Hoy is Assistant Professor and Assistant EntomoloA. Hoy is Assistant Professor and Assistant Entomolo-
gist at the University of California, Berkeley. Appreciagist at the University of California, Berkeley. Apprecia-
tion is expressed to Dennis Culver of ICI Americas, Inc., Visalia, and Earl Surber of Blackwell Farms, Blackwell's Corner, for their generous cooperation and to Wilbur Reil and Les Barclay for their logistical support. This project was supported by the Almond Board of California California Agricultural Experiment Staof California, California Agricultural Experiment Station Project No. 3522-H, and a National Science
dation Predoctoral Fellowship to the first author. 